\title{
A Judicialização do acesso à creche: desafios para um atendimento com qualidade
}

\author{
Juliana Andrade Vieira ${ }^{1}$ \\ http://orcid.org/0000-0003-2701-6347 \\ Sanny Silva da Rosa ${ }^{2}$ \\ http://orcid.org/0000-0001-5044-6156
}

\section{Resumo}

O artigo apresenta um panorama da judicialização da educação infantil no Brasil, focalizando os casos de vagas em creches municipais, com base em levantamento de estudos e pesquisas realizadas entre 2008 e 2019. Aborda e discute as tensões entre a garantia do direito à educação, prevista na legislação educacional brasileira, e o direito das famílias, dos bebês e das crianças pequenas a um atendimento com qualidade. Apresenta dados parciais de uma pesquisa em andamento sobre a judicialização do acesso em creches públicas do município de Santo André. Dada a complexidade do problema, conclui que, embora as reivindicações individuais tenham legitimidade, o problema precisa ser enfrentado com políticas públicas que reconheçam e garantam direitos coletivos arduamente conquistados no Brasil.

Palavras-chave: Judicialização da educação infantil. Direito à educação. Creches. Município de Santo André.

\begin{abstract}
The article presents an overview of the judicialization of early childhood education in Brazil out of studies and researches carried out between 2008 and 2019, focusing on the cases of municipal daycare centers. It addresses and discusses the tensions between the right to education, provided by Brazilian education law, and the right of families, babies and young children to a quality education and care. It presents partial data from an ongoing research on the judicialization of access to public daycare centers in the municipality of Santo André. Given the complexity of this issue, it concludes that although individual claims are legitimate, the lack of places needs to be addressed with public policies that recognize and guarantee some hard-won collective rights in Brazil.
\end{abstract}

Keywords: Judicialization of education. Right to day care. Child education.

\footnotetext{
${ }^{1}$ Pedagoga, licenciada em História, professora de educação infantil e ensino fundamental da Prefeitura Municipal de Santo André (creche) e de São Bernardo do Campo. Mestranda do Programa de pós-graduação em Educação da Universidade Municipal de São Caetano do Sul (USCS), Brasil. E-mail: ju_lianaandrade@hotmail.com

${ }^{2}$ Doutora em Educação (Currículo) pela PUC-SP; pós-doutoramento em políticas educacionais pelo Instituto de Educação da Universidade de Londres (UCL), UK. Professora e pesquisadora da linha de pesquisa Políticas e Gestão Educacional do Programa de Pós-graduação stricto sensu em Educação da Universidade Municipal de São Caetano do Sul, USCS, Brasil. E-mail: $\underline{\text { sanny.rosa@prof.uscs.edu.br }}$
} 


\section{Introdução}

O reconhecimento do direito dos bebês e crianças pequenas aos cuidados e à educação de que necessitam para crescerem e se desenvolverem de forma plena e com dignidade é fruto de um lento processo histórico no Brasil. Não é demais reforçar que, em relação à educação infantil, as conquistas legais tardiamente alcançadas, a partir da Constituição Federal de 1988, ocorreram por força da mobilização de gerações sucessivas de educadores que, a começar por aqueles que assinaram o Manifesto dos Pioneiros da Escola Nova, em 1932, mantiveram-se comprometidos e engajados em movimentos pela democratização da educação até a atualidade.

No caso do reconhecimento do direito à creche, os tímidos avanços observados ao longo do século XX, se devem, sobretudo, à luta de mulheres trabalhadoras - em especial as da região do ABC Paulista nos anos finais da década de 1970 (ROSEMBERG, 1984), por locais onde pudessem deixar seus filhos abrigados, de forma adequada e segura, durante suas longas jornadas de trabalho. Contudo, autores como Maria Malta Campos (1985) e Moysés Kuhlmann $\operatorname{Jr}$ (2000) não deixaram de registrar o descaso dos poderes públicos com essas instituições mesmo após terem sido incorporadas aos sistemas de ensino a partir da promulgação da atual Lei de Diretrizes e Bases da Educação Nacional (LDBEN), em 1996. Grande parte delas mantiveram os traços assistencialistas que remontam às práticas do Brasil do século XVIII.

Apesar de previsto em Lei (CF 88, art. 7, XXV) como um direito dos trabalhadores urbanos e rurais, as vagas em creches continuam sendo objeto de disputa das famílias de crianças pobres $^{3}$ em grande parte dos municípios brasileiros, cujos recursos, em geral, são insuficientes para atender a demanda por vagas. Embora não obrigatória na faixa etária de 0 a 3 anos, a educação obrigatória foi inserida, na CF de 1988, no rol dos direitos sociais de caráter público subjetivo. Considerando, ainda, que a educação é dever do Estado (CF, art. 208, IV) em regime de colaboração com os demais entes federativos (CF, art. 211), o poder público competente tornou-se passível de responsabilização. No caso das creches, os municípios passaram a ser o principal alvo de ações judiciais, desde então ${ }^{4}$.

Pode-se dizer assim que, por outros meios, o fenômeno da judicialização da educação dá sequência, na atualidade, à luta das mulheres-mães pela afirmação de seus próprios direitos e de seus filhos. Contudo, o número crescente de liminares concedidas pelo poder judiciário gera dificuldades que conflitam com outro direito: o de acesso a uma educação com padrões mínimos de qualidade. A tensão entre eles não afeta apenas as crianças, mas também os profissionais que atuam nas creches em função da superlotação dos espaços físicos, da precarização das

\footnotetext{
${ }^{3} \mathrm{O}$ direito à creche aos filhos de mães trabalhadoras foi reconhecido, pela primeira vez, no Brasil, na legislação trabalhista (art. 389 da Consolidação das Leis do Trabalho/ Decreto-Lei no 5.452/1943). O caráter assistencialista da creche se evidencia pelo foco da lei nas mães e não nas crianças (FERREIRA; CURY, s/d).

${ }^{4}$ Conforme Ferreira e Cury (s/d, p.2), esse entendimento ocorreu a partir do julgamento da RE 467255, em 22 de fevereiro de 2006, pelo Supremo Tribunal Federal.
} 
condições de atendimento e da intensificação do trabalho de professores, auxiliares e gestores.

Este artigo é parte de uma pesquisa em desenvolvimento que tem como foco, justamente, essa problemática no contexto da rede municipal de Santo André, município localizado da região do Grande ABC Paulista que tem se notabilizado pelo grande número de ações judiciais que reivindicam o direito de acesso a vagas em creches municipais.

Para tanto, o primeiro tópico situa o problema da judicialização da educação infantil no Brasil, apresentando o estado atual da questão discutida em estudos teóricos e pesquisas empíricas realizadas em diferentes municípios entre 2008 e 2019. Em seguida, o texto faz uma discussão sobre a qualidade da educação em creches, destacando as concepções de infância e de educação infantil que fundamentam diferentes documentos oficiais, produzidos ao longo das três últimas décadas no Brasil, e que trazem importantes contribuições para a definição de parâmetros de qualidade da educação e do atendimento em creche e pré-escolas. O terceiro e último tópico contém dados coletados junto à Prefeitura Municipal de Santo André e à Defensoria Pública do Estado de São Paulo, com o objetivo de oferecer um panorama geral dos desafios enfrentados pelos gestores de creches com vistas à garantia dos direitos fundamentais dos bebês e das crianças pequenas, em especial, as oriundas de famílias pertencentes às parcelas mais vulneráveis da população do município.

\subsection{A Judicialização do acesso a creches nas produções acadêmicas}

Com vistas a situar este estudo no contexto das produções acadêmicas sobre o tema, realizamos um levantamento no banco de dissertações e teses da Coordenação de Aperfeiçoamento de Pessoal de Nível Superior (CAPES), na Biblioteca Digital de Teses e Dissertações (BDTD), no portal de periódicos da Scielo (Scientific Electronic Library Online) e no Google Acadêmico, compreendendo o período de 2008 a 2019, década em que se verificou um crescimento significativo da judicialização da educação no Brasil (RANIERI, 2017).

Para tanto, primeiramente, foram utilizadas as palavras-chave "Judicialização" e "Qualidade da Educação", o que abriu um leque extenso de produções relacionadas as duas temáticas separadamente. Com o propósito de refinar as buscas, utilizou-se as palavraschave: "Judicialização $A N D$ Creches" e "Qualidade da educação infantil", o que restringiu o levantamento a 5 artigos, 8 dissertações e 2 teses. O Quadro 1 traz uma síntese dos trabalhos encontrados no recorte cronológico considerado, no subgrupo artigos, produzidos por acadêmicos do campo da Educação e do Direito. 
Quadro 1 - Artigos publicados (2008-2019)

\begin{tabular}{|c|c|c|c|}
\hline \multicolumn{5}{|c|}{ "Judicialização $A N D$ Creches" } \\
\hline Tipo de pesquisa & Título da Pesquisa & Nome do autor & $\begin{array}{c}\text { Ano de } \\
\text { Publicação }\end{array}$ \\
\hline Artigo & $\begin{array}{c}\text { A judicialização das relações } \\
\text { escolares e a responsabilidade civil } \\
\text { dos educadores }\end{array}$ & $\begin{array}{c}\text { CHRISPINO; } \\
\text { CHRISPINO }\end{array}$ & 2008 \\
\hline Artigo & A judicialização da Educação & CURY & 2010 \\
\hline Artigo & $\begin{array}{c}\text { Judicialização, ativismo judicial e } \\
\text { legitimidade democrática }\end{array}$ & BARROSO & 2012 \\
\hline Artigo & $\begin{array}{c}\text { Judicialização da educação: } \\
\text { interferência judicial aprofunda } \\
\text { desigualdade no acesso em creche por } \\
\text { quem mais precisa dele }\end{array}$ & LOMBARDI & 2014 \\
\hline Artigo & $\begin{array}{c}\text { Litígio estratégico para a mudança do } \\
\text { padrão decisório em direitos sociais: } \\
\text { ações coletivas sobre educação } \\
\text { infantil em São Paulo }\end{array}$ & RIZZI; XIMENES & 2014 \\
\hline Artigo & $\begin{array}{c}\text { A judicialização das Políticas } \\
\text { Públicas e o Direito à Educação } \\
\text { Infantil }\end{array}$ & TAPOROSKY; & 2019 \\
\hline
\end{tabular}

Fonte: Organizado pelas autoras

No artigo A judicialização das relações escolares e a responsabilidade civil dos educadores, os autores (CHRISPINO; CHRISPINO, 2008) sumarizam os principais casos de judicialização das relações escolares, dentre os quais não apareciam, ainda, questões relacionados ao acesso à creche ou à educação infantil por via judicial. Trazem, como exemplos, casos envolvendo obrigação de guarda e vigilância, danos morais, agressões e maus tratos de alunos, acidentes, entre outros. Contudo contribuem para pensar a problemática focalizada neste estudo ao chamarem a atenção para o fato de que professores e gestores têm dificuldade de lidar com as variáveis judiciais por desconhecerem os seus próprios deveres instituídos em dispositivos legais, como o Novo Código Civil e o Estatuto da Criança e do Adolescente, por exemplo. Além disso, o artigo indica um conjunto de ações que podem ser implementadas para que possam melhor compreender e lidar, no âmbito das relações escolares, com o binômio direito-deveres de todos os atores.

Em A judicialização da Educação, Cury e Ferreira (2010) relacionam o problema da judicialização com o histórico de ampliação dos direitos à educação no Brasil a partir da CF de 1988. Os autores também oferecem um panorama do conjunto de situações que podem envolver análise judicial no campo da educação, apontando seus efeitos no âmbito escolar, concluindo que: "A ausência de política pública que garanta o processo educacional, realizada de forma 
sistemática pela escola, acaba por acarretar medidas judiciais que interferem no cotidiano educacional" (CURY, FERREIRA, 2010, p. 44).

$\mathrm{Na}$ mesma linha de raciocínio, mas com escopo mais abrangente, o artigo de Barroso (2012) - Judicialização, ativismo judicial e legitimidade democrática - enfatiza que a democratização do país fortaleceu o poder judiciário, pois "o ambiente democrático reavivou a cidadania, dando maior nível de informação e de consciência de direitos a amplos segmentos da população, que passaram a buscar a proteção de seus interesses perante juízes e tribunais." (BARROSO, 2012, p. 3).

Tratando especificamente sobre o tema da creche, Lombardi (2014), no artigo Judicialização da educação: interferência judicial aprofunda desigualdade no acesso em creche por quem mais precisa dele, coloca a questão na perspectiva dos desafios enfrentados pelo administrador público. $\mathrm{O}$ autor, à época ocupando a posição de Secretário de Educação do município de Limeira (SP), pondera que a "escalada" da judicialização pode aprofundar as desigualdades sociais existentes, caso as políticas públicas definidas para enfrentar o problema da insuficiência de vagas não adotem o princípio de garantir a igualdade para os que são socialmente desiguais.

Rizzi e Ximenes (2014) contribuem para o aprofundamento dessas reflexões no artigo Litígio estratégico para a mudança do padrão decisório em direitos sociais: ações coletivas sobre educação infantil em São Paulo ao observarem que "a maneira excessivamente individualista de enxergar problemas que muitas vezes são coletivos parecem dificultar a apreciação judicial de direitos sociais" (p.4).

Sem negar o direito constitucional de acesso à educação, os argumentos apresentados por Taporosky e Silveira (2019), no artigo A judicialização das políticas públicas e o direito à Educação Infantil, corroboram muitas das ponderações feitas por Lombardi (2014), na medida em que questionam os limites de interferência do judiciário nos espaços e competências do executivo. Com esse propósito, os autores exploram, conceitualmente, as noções de justiciabilidade do direito e de judicialização, bem como discorrem sobre a teoria da reserva do possível, concluindo que a atuação do Poder Judiciário se faz legítima, mas que "há limitações que deverão ser observadas pelo Poder Judiciário para que não substitua a Administração Pública no exercício de sua função constitucional (TOPOROSKY; SILVEIRA, 2019, p. 309).

Os aspectos considerados nesses trabalhos, a diversidade de conceitos e argumentos apresentados para examinar a judicialização da vida social no Brasil, tanto sob a perspectiva do Direito, como da Educação, apontam para a complexidade do tema, e servem para alertar os pesquisadores quanto ao risco de fazer afirmações ou firmar posições sem antes ponderar, com rigor, os diversos aspectos implicados nessa problemática.

O segundo subgrupo de estudos correlatos concentra as dissertações e teses encontradas nos bancos de dados consultados entre 2008 e 2019. É possível perceber, pelo Quadro 2, que 
as produções sobre o tema se intensificaram nos últimos três anos, chamando a atenção de pesquisadores de diferentes campos do conhecimento, como Políticas Públicas, Administração Pública, Direito e Educação.

Quadro 2 - Dissertações e Teses (2008-2019)

\begin{tabular}{|c|c|c|c|}
\hline \multicolumn{5}{|c|}{ "Judicialização $A N D$ Creches" } \\
\hline Tipo de pesquisa & Nome do autor & $\begin{array}{c}\text { Ano de } \\
\text { Publicação ou } \\
\text { Defesa. }\end{array}$ \\
\hline Dissertação & $\begin{array}{c}\text { Análise dos efeitos da judicialização } \\
\text { da política pública de educação } \\
\text { infantil: o caso de Santo André (SP) }\end{array}$ & SANTOS & 2014 \\
\hline Dissertação & $\begin{array}{c}\text { A Judicialização do direito à } \\
\text { educação: o caso brasileiro sob a } \\
\text { perspectiva da mobilização social }\end{array}$ & ERHARDT & 2017 \\
\hline Dissertação & $\begin{array}{c}\text { A judicialização na expansão das } \\
\text { vagas em creches: o diálogo entre } \\
\text { poder judiciário e poder executivo }\end{array}$ & ROSÁRIO & 2017 \\
\hline Tese & $\begin{array}{c}\text { Creche: do direito à educação à } \\
\text { judicialização da vaga' }\end{array}$ & POLONI & 2017 \\
\hline Dissertação & $\begin{array}{c}\text { O trabalho docente frente à } \\
\text { judicialização de vagas nas creches: } \\
\text { sentidos de professores }\end{array}$ & JOCHI & 2018 \\
\hline Dissertação & $\begin{array}{c}\text { Defensoria pública na judicialização } \\
\text { da educação infantil no município } \\
\text { de São Paulo: efeitos institucionais } \\
\text { sobre as políticas públicas }\end{array}$ & SILVA & 2018 \\
\hline
\end{tabular}

Fonte: Organizado pelas autoras

Apresentado como trabalho final de Mestrado à Escola de Administração de Empresas de São Paulo da Fundação Getúlio Vargas, em 2014, a dissertação de Marinella Burgos Pimentel Dos Santos teve como foco específico a problemática que interessa diretamente à nossa pesquisa: os efeitos da judicialização da política pública de Educação Infantil, particularmente, no que se refere às creches municipais. Um ponto importante identificado nesse estudo é o de que a judicialização do acesso à vaga em creche acarreta "um real prejuízo àquelas crianças que não buscam apoio no sistema judiciário e permanecem nas listas de espera aguardando a sua chance de ingressar no sistema educacional" (SANTOS, 2014, p. 23).

Sendo assim, a pesquisadora alerta que o princípio da isonomia tem sido ferido na busca de obtenção de vantagens individuais. Mais grave do que isso, a autora adverte sobre a necessidade de estudos mais aprofundados sobre o caso específico de Santo André em que "há relatos de que esteja havendo uma espécie de 'comercialização das vagas', por parte de 
escritórios de advocacia interessados em captar clientes que buscam garantir acesso ao serviço público. Em suas conclusões, a pesquisadora se refere às tensões e desafios que se colocam frente ao imperativo de respeitar esses dois direitos constitucionais: o de acesso à educação, mas também a padrões mínimos de qualidade de atendimento nas instituições de ensino. Sobre isso, observa:

\begin{abstract}
Nesse contexto, a ânsia de cada um de buscar garantir o direito individual pode levar ao não cumprimento do direito coletivo, uma vez que o excesso no número de alunos em uma mesma sala de aula e com professores insuficientes pode levar danos às próprias crianças. A questão da qualidade do atendimento em contraponto com a quantidade de atendidos talvez seja o desafio mais importante a ser exaustivamente debatido na questão da judicialização da política pública de Educação Infantil (SILVA, 2014, p. 24).
\end{abstract}

Maria José Poloni (2017), em sua tese de doutorado, defendida no Programa de Pós-graduação em Educação da Universidade Nove de Julho (UNINOVE), abordou o tema da judicialização por vagas em creches em outro município localizado na região do Grande ABC Paulista. A pesquisadora abordou o tema no contexto de uma discussão mais ampla sobre o direito à educação, tanto sob a ótica da legislação, como também da perspectiva de pais, professores e gestores de creches do município de Mauá. Em suas considerações finais, ressalta aspectos social e historicamente relevantes sobre o fenômeno da judicialização: de um lado, que ele "reflete um movimento de conscientização em construção", mas, de outro, que ainda "resulta de ações isoladas de famílias que [...] enfrentam à sua maneira o problema da negação desse direito" (POLONI, 2017, p. 236).

André Cavalcanti Erhardt (2017), defendeu sua dissertação de mestrado em Direito na Universidade de Brasília, na qual investigou a concretização do direito social à educação pelo Poder Judiciário brasileiro. O estudo faz uma análise da evolução dos direitos sociais nas diferentes Constituições brasileiras, sustentando que a crescente intervenção judicial nas políticas públicas não se deve apenas à ampliação de dispositivos normativos e constitucionais, mas, sobretudo, à mobilização dos interesses em concretizá-los. Dentre as demandas judiciais analisadas, o pesquisador ressalta o grande número de reivindicações por vagas em creches e pré-escolas em todo o país e aponta a importância da mobilização da sociedade civil organizada na busca por garantias de direitos.

Marcela Inafuku Rosário (2017), desenvolveu sua pesquisa de mestrado no Programa de Formação de Gestores Educacionais da Universidade Cidade de São Paulo (UNICID), analisando o processo de judicialização das vagas em creches e o diálogo entre o poder judiciário e executivo do município de São Paulo, a partir da sentença que condenou a prefeitura a matricular 150 mil crianças em creches e pré-escolas, em 2013. Nesse estudo qualitativo, a pesquisadora fez entrevistas com membros do Comitê de Monitoramento do Plano de Expansão 
de vagas em creches, enfatizando também a importância desses atores para democratizar a relação entre o poder executivo, judiciário e a sociedade civil.

Tomando como objeto o mesmo episódio desencadeado, em 2013, no município de São Paulo, a dissertação de mestrado de Mariana Pereira da Silva, defendida, em 2018, no Programa de Políticas Púbicas da Universidade Federal do ABC (UFABC), investigou os efeitos da judicialização das políticas públicas de educação infantil na Defensoria Pública do Estado de São Paulo. Desse processo, resultaram efeitos diretos, como o estabelecimento de novos fluxos administrativos por parte da Defensoria Pública, a criação de um sistema de monitoramento da demanda por vagas em creches e o desenvolvimento e implementação de um plano de expansão da rede pela administração municipal. Como efeitos indiretos, mudanças institucionais importantes, como a criação de um Grupo de Trabalho Interinstitucional sobre Educação Infantil (GTEI) e de um Comitê de Assessoramento, com a participação da sociedade civil e de pesquisadores do campo educacional, contribuíram para a melhoria do diálogo entre poder judiciário e executivo e para o amadurecimento das instituições de justiça. Vale mencionar que elementos significativos dessa pesquisa foram objeto de reflexões apresentadas no artigo de Ximenes, Pereira e Silva (2019).

Por fim, a dissertação de mestrado de Fabiana Joschi (2018,) focalizou a judicialização sob a ótica dos professores de uma creche do município de Sorocaba, localizado no interior do estado de São Paulo. De caráter qualitativo, a pesquisa constatou que, apesar das alternativas criadas por professores e gestores, restam muitas dificuldades geradas pela concessão de liminares, particularmente, o número insuficiente de profissionais, a precarização do trabalho docente e a crescente terceirização dos serviços por meio da contratação de estagiários que atuam como auxiliares de educação nas creches do município.

Do conjunto dos estudos selecionados nesse levantamento foi possível extrair algumas constatações. Duas delas são especialmente relevantes para os pesquisadores ocupados com a judicialização do direito à educação. A primeira, como já ressaltamos, é que essa é uma discussão de alta complexidade, não apenas porque impõe considerar múltiplas variáveis, muitas delas conflitantes entre si, mas porque cada caso particular suscita colocar em relevo princípios jurídicos, éticos e políticos de difícil conciliação. A segunda é que, intrínseco a esse debate, em todos os casos se coloca, como contraponto, as condições concretas das autoridades competentes de arcar com o dever de ofertar um atendimento de acordo com os padrões mínimos de qualidade a que têm direito os bebês, as crianças pequenas e suas famílias.

Embora intensa e recorrentemente discutido, o tema da qualidade da educação e, em particular, o da qualidade da educação infantil em creches, permanece polêmico. Dentro dos limites deste texto, procuraremos situar o estado atual da questão, posto que se impõe como ponto nevrálgico da problemática investigada em nossa pesquisa. 


\section{Qualidade da educação em creches: uma promessa a ser cumprida}

Ainda que diversos avanços tenham sido empreendidos pela Ciência desde o Século XIX na direção de compreender como as crianças se desenvolvem, pensam, agem e se socializam, em pleno caminhar do Século XXI, ainda impera a concepção pré-moderna e de senso comum de que elas são "adultos em miniatura" (ARIÈS, 1986). Evidência disso, no Brasil atual, é que parcela considerável da sociedade vê com simpatia o anúncio oficial ${ }^{5}$ de que o Brasil estaria entrando em uma "nova era", em que "menino veste azul e menina veste rosa".

Essa visão reduzida e moralista da infância, contudo, há muito foi superada por estudiosos e formuladores de políticas públicas de educação infantil. Documentos oficiais foram produzidos, em diferentes gestões do governo federal nas últimas décadas, visando orientar professores e gestores educacionais a planejar o currículo e conduzir as práticas pedagógicas nas instituições escolares, tendo como referência uma vasta e rica produção acadêmica, nacional e internacional, fundamentada em conhecimentos dos campos da biologia, da psicologia, da sociologia da infância, entre outros.

A despeito de discordâncias pontuais, estamos a anos-luz de distância desse tipo de formulação doméstica marcada por valores religiosos e concepções obscurantistas, pois há tempos existe certo consenso entre os educadores a respeito de que as crianças são seres sociais e, portanto, sujeitos de direitos. Pois, como afirma este autor:

[...] as crianças são agentes sociais, ativos e criativos, que produzem suas próprias e exclusivas culturas infantis, enquanto, simultaneamente, contribuem para a produção das sociedades adultas. [...] a criança é vista como agente ativo e um ávido aprendiz. Sob essa perspectiva, a criança constrói ativamente seu mundo social e seu lugar nele (CORSARO, 2011, p.15-19).

Contribuições importantes da área de educação infantil, publicadas ao longo dos anos de 1980, 1990, e mais particularmente, na primeira década dos anos 2000, foram objeto de estudo em cursos de formação de professores e em programas de educação continuada com vistas à melhoria da qualidade do atendimento às crianças pequenas, particularmente, nos sistemas públicos de ensino. Em artigo publicado no final dos anos 1990, Maria Lúcia Machado, já argumentava que "crianças expostas a uma gama ampliada de possibilidades interativas têm seu universo pessoal de significados ampliado, desde que se encontrem em contextos coletivos de boa qualidade" (MACHADO, 1999, p 91).

\footnotetext{
${ }^{5}$ Fala de Damares Alves, em seu discurso de posse como Ministra da pasta da Mulher, Família e Direitos Humanos, criada pelo governo de Bolsonaro. 03 jan. 2019. Disponível em: https://www1.folha.uol.com. br/poder/2019/01/menino-veste-azul-e-menina-veste-rosa-diz-damares.shtml. Acesso em 29 jan. 2020 .
} 
Focalizando preferencialmente as creches, um documento do Ministério da Educação (MEC/SEB, 2009), publicado em 1995 e reeditado em 2009, foi organizado por Maria Malta Campos e Fúlvia Rosemberg, no qual estão descritos critérios de qualidade e atendimento às crianças pequenas. De forma bastante didática, a primeira parte do documento tem como objetivo subsidiar o trabalho de planejamento e avaliação dos profissionais de creche.

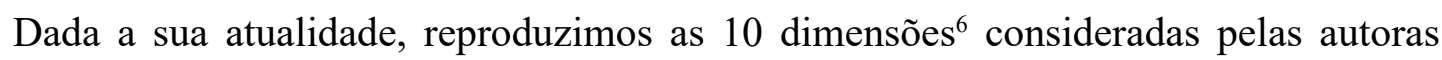
como essenciais para atender as necessidades fundamentais das crianças pequenas em creches.

- Nossas crianças têm direito a um ambiente aconchegante, seguro e estimulante;

- Nossas crianças têm direito ao contato com a natureza;

- Nossas crianças têm direito a higiene e à saúde;

- Nossas crianças têm direito a uma alimentação sadia;

- Nossas crianças têm direito a desenvolver sua curiosidade, imaginação e capacidade de expressão;

- Nossas crianças têm direito ao movimento em espaços amplos;

- Nossas crianças têm direito à proteção, ao afeto e à amizade;

- Nossas crianças têm direito a expressar seus sentimentos;

- Nossas crianças têm direito a uma especial atenção durante seu período de adaptação à creche $\mathrm{e}$

- Nossas crianças têm direito a desenvolver sua identidade cultural, racial e religiosa.

Com o objetivo de induzir as políticas educacionais para a educação infantil nos estados e municípios, a Secretaria de Educação Básica do MEC produziu dois outros documentos que merecem ser mantidos na "mesa de cabeceira" dos educadores e utilizados por gestores públicos e profissionais politicamente comprometidos com a redução das desigualdades sociais que, hoje, tendem a se aprofundar no Brasil7.

O primeiro deles, organizado em dois volumes, são os Parâmetros Nacionais de Qualidade para a Educação (MEC/SEB, 2006), que oferece pontos de partida para que os sistemas educacionais possam definir objetivos, estabelecer metas, monitorar as ações e avaliar as políticas de educação infantil. O segundo - Indicadores de Qualidade na Educação Infantil (MEC/SEB, 2009) - é mais operacional e se dirige diretamente às instituições de ensino, de modo que possam, efetivamente, monitorar a qualidade do trabalho que desenvolvem. Vale citar, ainda, as Diretrizes Curriculares Nacionais para a Educação Infantil - DCNEI (BRASIL,

\footnotetext{
${ }^{6}$ Indicadores de qualidade de cada uma das dimensões são detalhados nesse documento, de modo a viabilizar o trabalho de autoavaliação e planejamento pelos profissionais de creche. A íntegra do documento pode ser acessada no link: http://portal.mec.gov.br/dmdocuments/direitosfundamentais.pdf

${ }^{7}$ Sobre o assunto, ver estudo “A Escalada da Desigualdade...”, realizado pelo Centro de Políticas Sociais da FGV, divulgado em novembro de 2019. Disponível em: :https://cps.fgv.br/desigualdade. Acesso em: 29 jan. 2020.
} 
2010) que orientam a organização curricular e pedagógica das instituições de educação infantil, além de oferecer parâmetros de qualidade para o atendimento em creches e pré-escolas de todo o país.

É especialmente importante registrar, face à retração das práticas democráticas do Estado e da sociedade brasileira nos dias que correm, a forma democrática com que esses documentos foram produzidos. Todos eles foram amplamente discutidos com representantes de todos os entes federados (estados/municípios/DF), com comunidade científica e profissional da área, em Seminários regionais e nacionais. Nesse sentido, esses materiais constituem registros históricos importantes de que é possível fazer política pública respeitando as diferenças e seguindo as regras do jogo democrático.

Com efeito, quando as políticas públicas são tiradas do papel e colocadas em ação, geralmente encontram, e se conflitam, com uma série de meandros e contingências sociais, políticas e jurídicas nem sempre passíveis de previsão por parte de seus formuladores. $O$ fenômeno da judicialização da educação, objeto deste trabalho, é em parte efeito desse desencontro e, em grande medida, fere o direito à qualidade da educação também previsto em nossa legislação maior (CF, art. 206, VII; LDB, art. 4, IX), normatizada em vários outros dispositivos legais, como a Resolução no 5, de 17/02/09 do CNE e a Resolução no 4, de 13/ 07/10).

Em artigo publicado na página eletrônica do Ministério Público do Estado de São Paulo, Carlos Roberto Jamil Cury e Luiz Antônio Miguel Ferreira ${ }^{8}$ tocam em um ponto sensível, mas essencial, quando se busca pensar a relação entre judicialização e qualidade da educação infantil: “O problema é que não se pode analisar esta questão relacionando-a apenas ao direito individual ou coletivo. Há necessidade de se seguir parâmetros de qualidade, sob pena de transformar as creches em depósitos de crianças" (FERREIRA, CURY, s/d, p. 8).

Os autores lembram, ainda, que é preciso respeitar o que estabelece o Parecer 20/09, homologado em 09/12/09 sobre a proporção professor/aluno em diferentes faixas etárias.

O número de crianças por professor deve possibilitar atenção, responsabilidade e interação com as crianças e suas famílias. Levando em consideração as características do espaço físico e das crianças, no caso de agrupamentos com criança de mesma faixa de idade, recomenda-se a proporção de 6 a 8 crianças por professor (no caso de crianças de zero e um ano), 15 crianças por professor (no caso de criança de dois e três anos) e 20 crianças por professor (nos agrupamentos de crianças de quatro e cinco anos) (BRASIL, 2009, p. 13)

Vale lembrar também que o Conselho Nacional de Educação, em seu Parecer nº 8/2010, estabeleceu normas para a aplicação do inciso IX, artigo $4^{\circ}$, da Lei $n^{\circ}$ 9. 394/96 (LDB), que trata

\footnotetext{
${ }^{8}$ Os autores têm se dedicado a estudar a judicialização da educação e publicado trabalhos conjuntos sobre o tema desde 2009, quando o fenômeno se intensificou no Brasil. A consistência de tais estudos se deve, em grande medida, à articulação e complementaridade das áreas de formação dos dois autores (Educação e Direito), incomum entre tomadores de decisão de diferentes esferas do poder público.
} 
dos padrões mínimos de qualidade de ensino para a Educação Básica Pública. O Custo Aluno Qualidade Inicial (CAQi) - criado pela Campanha Nacional pelo Direito à Educação, que afere o quanto o Brasil precisa investir por aluno para alcançar um padrão mínimo de qualidade do ensino - estabeleceu requisitos para a realização desse cálculo, e um deles se refere ao tamanho das turmas:

[...] 4. A definição de uma relação adequada entre o número de alunos por turma e por professor, que permita uma aprendizagem de qualidade. Nessa proposta, as seguintes relações aluno/professor por turma foram consideradas: (a) Creche: 13 crianças [...] Assim, o CAQi foi construído, no que se refere ao número de salas e alunos, com as seguintes características: uma Creche com 130 crianças (10 salas e 10 turmas). (BRASIL, 2010, p. 19).

É certo que o debate acerca do conceito de qualidade é, e sempre será polêmico, uma vez que o termo é marcado por subjetividades e, portanto, sujeito a diferentes interpretações e pontos de vista. Contudo, é preciso admitir que, objetivamente falando, já contamos com referências suficientes, fruto de muitas discussões, debates, estudos, pesquisas e, mais, do amadurecimento político alcançado nas últimas três décadas de experiência democrática, para afirmarmos, com alguma segurança o que não é qualidade.

É preciso reconhecer também que todo esse esforço se encontra materializado em nossa legislação, nos documentos oficiais aqui mencionados e outros mais, como o Estatuto da Criança e do Adolescente (Lei n. 8.069/1990), a Lei n. 11.494/2007 que regulamentou o Fundo de Manutenção e Desenvolvimento da Educação Básica e de Valorização dos Profissionais da Educação (FUNDEB) que, em seu conjunto, constituem um patrimônio político histórico a ser preservado pela sociedade brasileira e, em particular, pelos educadores.

A despeito de tantos avanços, o trajeto percorrido foi muito pequeno diante da imensa dívida social que ainda temos com os bebês e crianças pequenas pobres de nosso país. Para ilustrar os obstáculos que ainda precisam ser vencidos para converter direitos proclamados em ações concretas, trazemos, no próximo tópico, alguns dados já coletados em nosso estudo relativos à situação vivida nas creches públicas do município de Santo André, na região do $\mathrm{ABC}$ Paulista.

\section{A judicialização do direito a creches em Santo André: panorama em construção}

De acordo com dados da Fundação SEADE (2020), o município de Santo André possui, hoje, uma população 693.867 habitantes, com uma densidade populacional de 3.947,36 hab/ $\mathrm{km}^{2}$, distribuída em um território que compreende 175,78 $\mathrm{Km}^{2}$. Em 2013, a cidade comemorou o idH/Pnud, ao ocupar o $14^{\circ}$ lugar entre os 5.570 municípios brasileiros.

Entretanto, conforme observou Miranda (2005, p.67), "Santo André, apesar de ser 
um município com nível elevado de riqueza e bons níveis nos indicadores sociais do IPRS da Fundação Seade, não atingiu a meta de 50\% de atendimento de crianças de 0 a 3 anos em creches em 2010". Vale mencionar que, de acordo com projeções baseadas do Censo de 2010 (IBGE), o número estimado de crianças de 0 a 3 anos, em 2018, seria de 33.040.

A Tabela 2 apresenta a evolução do número de matrículas em creches por dependência administrativa (pública/privada), no município de Santo André entre 2010 e 2018, com base em dados do Censo Escolar do Ministério da Educação (MEC/INEP).

Tabela 2 - Evolução de Matrículas em Creches do Município de Santo André (2010-2018)

\begin{tabular}{|c|c|c|c|c|c|c|}
\hline Ano & $\begin{array}{c}\mathrm{N}^{\circ} \text { total de } \\
\text { matrículas }\end{array}$ & $\begin{array}{c}\text { Total de } \\
\text { creches }\end{array}$ & $\begin{array}{c}\text { Creches } \\
\text { públicas }\end{array}$ & $\begin{array}{c}\text { Creches } \\
\text { privadas }\end{array}$ & $\begin{array}{c}\mathrm{N}^{\circ} \text { matrículas em } \\
\text { creches públicas }\end{array}$ & $\begin{array}{c}\mathrm{N}^{\circ} \text { matrículas em } \\
\text { creches privadas }\end{array}$ \\
\hline 2010 & 9427 & 215 & 25 & 190 & 3358 & 6069 \\
\hline 2014 & 13277 & 240 & 42 & 198 & 6018 & 7259 \\
\hline 2016 & 14493 & 248 & 49 & 199 & 7323 & 7170 \\
\hline 2017 & 14541 & 229 & 44 & 185 & 7725 & 6816 \\
\hline 2018 & 14800 & 225 & 43 & 182 & 8049 & 6751 \\
\hline
\end{tabular}

Fonte: Organizada pelas autoras com dados do Censo Escolar Inep 2010-2018

Os dados da tabela acima revelam não apenas o crescimento constante do número de matrículas em creches no município de Santo André, como a grande desproporção do número de crianças por tipo de estabelecimento. Tomando apenas os números de 2018, observa-se que os estabelecimentos particulares recebem, em média, 37 crianças por ano, enquanto as creches públicas recebem 187. Chama a atenção também que o número de estabelecimentos privados (creches) no município é 4,2 vezes maior do que os públicos, uma realidade totalmente distorcida que se mantém ao longo do tempo.

O Gráfico 1, reproduzido do relatório "Panorama da Pobreza em Santo André” (SANTO ANDRÉ, 2015), apresenta a situação de matrículas em creche do ponto de vista geográfico, considerando dados do ano de 2013. Nesse mapa, chama a atenção o número maior de crianças que não frequentavam a escola (creche) em Áreas de Ponderação (bairros) que concentram a população mais vulnerável do município e que apresentam condições mais precárias de moradia. Como exemplo, o bairro Cata Preta, apresentava "um total de 12.664 pessoas, com renda per capita de até 1/2 salário mínimo." (SANTO ANDRÉ, 2015, p.37). 
Gráfico 1 - Frequência de crianças de 0 a 3 anos em creches*

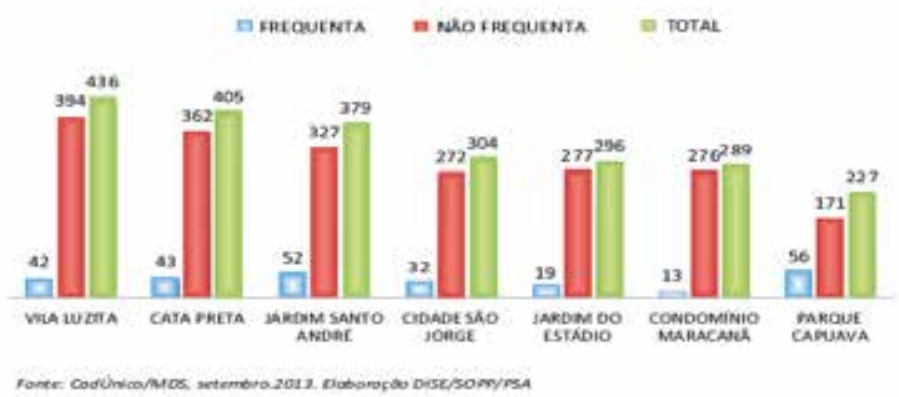

Fonte: Panorama da Pobreza em Santo André - 2013

Quando comparamos o gráfico acima com a distribuição das liminares concedidas pela Defensoria Pública entre 2015 a março de 2018 (Tabela 2), verificamos que a geografia do problema se concentra nos locais de moradia das populações mais carentes do município.

Tabela 2 - Bairros de Santo André x número de liminares (2015-2018)

\begin{tabular}{|c|c|c|c|c|c|c|}
\hline Ranking & Bairro & 2015 & 2016 & 2017 & $\begin{array}{c}2018 \text { (até } \\
\text { março) }\end{array}$ & Total \\
\hline 1. & Jd. Santo André & 74 & 116 & 94 & 46 & 330 \\
\hline 2. & Jd. Alzira Franco & 35 & 64 & 54 & 12 & 165 \\
\hline 3. & Cidade São Jorge & 36 & 62 & 45 & 7 & 150 \\
\hline 4. & $\begin{array}{c}\text { Recreio da Borda } \\
\text { do Campo }\end{array}$ & 26 & 47 & 28 & 14 & 115 \\
\hline 5. & $\begin{array}{c}\text { Condomínio } \\
\text { Maracanã }\end{array}$ & 22 & 46 & 30 & 8 & 106 \\
\hline $\begin{array}{c}\text { Total das } \\
\text { escolas: }\end{array}$ & 6520 & 1266 & 1002 & 904 & 3824 \\
\hline
\end{tabular}

Fonte: Elaborada pelas autoras, com dados da Defensoria Pública - 2019

Com um total acumulado de 3.824 liminares concedidas em pouco mais de três anos, Santo André enfrenta, atualmente, situação semelhante à descrita por diversos pesquisadores dessa temática. Considerando, ainda, que o número aproximado de professores nas creches públicas desse município é de 645 (INEP, 2018), pode-se imaginar a dimensão das dificuldades e desafios enfrentados pelos profissionais para dar conta das tarefas de cuidar e educar em salas superlotadas entre outras insuficiências de infraestrutura e de recursos materiais.

No dia a dia das creches, esses desafios e demandas recaem, inexoravelmente, nas mãos dos gestores, razão pela qual esses sujeitos estarão no centro das preocupações desta investigação ainda em desenvolvimento. Contudo, o cenário construído até o momento já é suficiente para afirmar que Santo André necessita de maiores investimentos e políticas públicas adequadas para garantir as condições necessárias para que esses profissionais possam cumprir o seu papel. 


\section{Considerações finais}

Procuramos oferecer neste artigo um panorama geral do estado atual das pesquisas e estudos sobre a judicialização do acesso a vagas em creches no Brasil. Desse levantamento resulta a constatação da dimensão e gravidade desse crescente fenômeno de alta complexidade vivido em grande parte dos municípios brasileiros, mas que, ao fim e ao cabo, afeta principalmente as crianças das famílias pobres que não veem outra alternativa senão apelar para a "Justiça", como é o caso do município de Santo André.

A própria existência da tensão entre a afirmação do direito de acesso a uma vaga em creche e o direito a um atendimento com qualidade é sinal alarmante das sequelas de um processo histórico marcado por negligências e insuficiências que se apresentam, atualmente, como um problema crônico de difícil solução. $\mathrm{O}$ embate entre quantidade e qualidade significa que continuamos a ver os direitos das crianças e das famílias desrespeitados, sobretudo os da população mais necessitada que continua na espera de políticas efetivamente comprometidas com a democratização da educação e com a redução das desigualdades sociais no Brasil.

Como bem argumentam os estudiosos do assunto, não se trata de negar a legitimidade das reivindicações de iniciativa individual, mas de encontrar saídas em políticas que reconheçam e façam valer direitos coletivos a duras penas conquistados, sobretudo, a partir da Constituição de 1988. Diante desse cenário, cabe aos pesquisadores examinar de perto a forma como esse problema vem sendo equacionado pelos poderes públicos e os efeitos por ele gerados nas unidades de ensino. Mais do que um interesse acadêmico, investigar essa temática é um modo de manter-se atento e de resistir às ameaças prenunciadas em tempos de retrocessos.

\section{Referências}

ARIÈS, Philippe. História social da criança e da família. Trad. Dora Flaksman. 2. ed. Rio de Janeiro: Guanabara, 1986.

BARROSO, Luis Roberto. Barroso. Judicialização, ativismo judicial e legitimidade democrática. (Syn)Thesis, Rio de Janeiro, v. 5, n. 1 p. 23-32, 2012. Disponível em: https:// www.e-publicacoes.uerj.br/index.php/synthesis/article/view/7433/5388 Acesso em: 10 jan. 2020.

BRASIL. Constituição da República Federativa do Brasil, de 05 de outubro de 1988. Disponível em: http://www.planalto.gov.br/ccivil 03/constituicao/constituicao.htm Acesso em: 05 jan. 2020.

BRASIL. [Presidência da República]. Lei nº 8.069, de 13 de julho de 1990. Estatuto da Criança e do Adolescente - ECA. Disponível em: http://www.planalto.gov.br/Ccivil 03/leis/ 
BRASIL. [Ministério da Educação/Secretaria da Educação Básica]. Critérios para um atendimento em creches que respeite os direitos fundamentais das crianças/Maria Malta Campos e Fúlvia Rosemberg. - $1^{\mathrm{a}}$. ed. 1995. $6^{\mathrm{a}}$. ed. Brasília: MEC,SEB, 2009. Disponível em: http://portal.mec.gov.br/dmdocuments/direitosfundamentais.pdf Acesso em: 05 jan. 2020.

BRASIL. [Presidência da República]. Lei no 9.394, de 20 de dezembro de 1996. Lei de Diretrizes e Bases da Educação Nacional. Disponível em: http:/www.planalto.gov.br/ Ccivil 03/leis/L9394.htm. Acesso em: 05 jan. 2020.

BRASIL. [Ministério da Educação. Secretaria de Educação Básica]. Parâmetros nacionais de qualidade para a educação infantil. Ministério da Educação. Secretaria de Educação Básica: Brasília (DF), 2006. Disponível em: http://portal.mec.gov.br/seb/arquivos/pdf/ Educinf/eduinfparqualvol1.pdf Acesso em: 05 jan.2020

BRASIL. [Ministério da Educação. Conselho Nacional de Educação. Câmara de Educação Básica]. Parecer CNE/CEB no 20/2009. Aprovado em 11 novembro 2009. Disponível em: http://portal.mec.gov.br/dmdocuments/pceb020_09.pdf. Acesso em: 05 jan. 2020

BRASIL. [Ministério da Educação. Conselho Nacional de Educação. Câmara de Educação Básica]. Resolução n. 05, de 17 de dezembro de 2009. Fixa as Diretrizes Curriculares Nacionais para a Educação Infantil. Disponível em: http://www.seduc.ro.gov.br/portal/ legislacao/RESCNE005 2009.pdf Acesso em: 07 jan. 2020.

BRASIL. [Ministério da Educação/Secretaria da Educação Básica]. Indicadores da Qualidade na Educação Infantil. Ministério da Educação. Secretaria de Educação Básica: Brasília (DF), MEC/SEB, 2009. Disponível em: http://portal.mec.gov.br/dmdocuments/indic qualit_educ infantil.pdf. Acesso em: 05 jan. 2020

BRASIL. [Ministério da Educação. Conselho Nacional de Educação. Câmara de Educação Básica]. Resolução n. 04, de 13 de julho de 2010. Define Diretrizes Curriculares Nacionais Gerais para a Educação Básica. Disponível em: http://portal.mec.gov.br/dmdocuments/ rceb004_10.pdf Acesso em: 06 jan.2020.

BRASIL. Instituto Nacional de Estudos e Pesquisas Educacionais Anísio Teixeira.

Plano Nacional de Educação PNE 2014-2024: Linha de Base. - Brasília, DF : Inep, 2015. Disponível em: http://portal.inep.gov.br/documents/186968/485745/Plano+Na

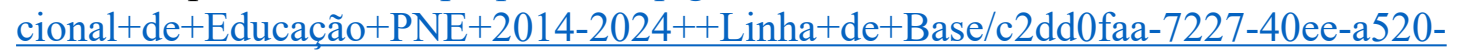
12c6fc77700f?version=1.1 Acesso em: 05 jan. 2020.

CHRISPINO, Álvaro; CHRISPINO, Raquel S. P. A judicialização das relações escolares e a responsabilidade civil dos educadores. Ensaio: aval.pol.públ.Educ., Rio de Janeiro, v. 16, n. 58, p. 9-30, jan/mar. 2008. Disponível em: http://www.scielo.br/pdf/ensaio/v16n58/a02v1658. pdf Acesso em: 08 jan. 2020. 
CORSARO, W. A. Sociologia da Infância. Porto Alegre: Artemed, 2011.

CURY, Carlos Roberto Jamil; FERREIRA, Luis Antônio Miguel A judicialização da educação. In: FERREIRA, A.M.F. Temas de Direito à Educação. São Paulo: Imprensa Oficial: Escola Superior do Ministério Público, 2010, p. 53-94.

CURY, Carlos Roberto Jamil; FERREIRA, Luis Antônio Miguel. Judicialização da educação infantil, o trabalho dos professores e a qualidade da educação: relações possíveis. In: Ministério Público do Estado de São Paulo (MPSP). Textos. São Paulo, s/d. Disponível em: http://www.mpsp.mp.br/portal/page/portal/Educacao/ensino_infantil_creches/textos_ens inf creches. Acesso em: 29 jan. 2020.

FUNDAÇÃO SEADE. [Fundação Sistema Estadual de Análise de Dados/Secretaria de Governo do Estado de São Paulo]. Perfil dos Municípios Paulistas, s/d. Disponível em: https://perfil.seade.gov.br

JOSCHI, Fabiana A.P. O trabalho docente frente à Judicialização de vagas nas creches: sentidos de professores, 2018. Dissertação [Mestrado em Educação]. Pós-graduação em Educação da Universidade Federal de São Carlos, Sorocaba, 2018.

KUHLMAN JR., Moysés. Histórias da educação infantil brasileira. Rev. Bras. Educ., Rio de Janeiro, n. 14, p. 5-18, ago. 2000.

LOMBARDI, José C. Judicialização da educação: interferência judicial aprofunda desigualdade no acesso em creche por quem mais precisa dele. Revista HISTEDBR, v. 14 n. 57, p. 388-397. jun. 2014

MACHADO, Maria Lúcia de A.. Criança pequena, educação infantil e formação dos profissionais. Perspectiva, Florianópolis, v. 17, n. 1, p. 85-98, jan. 1999. ISSN 2175-795X. Disponível em: https://periodicos.ufsc.br/index.php/perspectiva/article/view/10549/10087. Acesso em: 05 jan. 2020

MIRANDA, N. A.; APARÍCIO, A. S. M.; ANDRADE, M. F. R. A educação infantil nas cidades do consórcio do Grande ABC e o Plano Nacional de Educação: avanços e retrocessos. EccoS, São Paulo, n. 37, p. 59-75. maio/ago. 2015.

POLONI, Maria José. Creche: do direito à educação à judicialização da vaga. 2017. Tese [Doutorado em Educação] Universidade Nove de Julho, São Paulo, 2017.

RANIERI, Nina Beatriz Stocco. Panorama da judicialização do direito à Educação no Supremo Tribunal Federal entre 2000 e 2015. In: Reflexões sobre justiça e educação / [organização Todos pela Educação, Editora Moderna]. — 1. ed. — São Paulo : Moderna, 2017. Disponível em: https://todospelaeducacao.org.br/ uploads/posts/19.pdf Acesso em: 28 jan. 2020.

ROSÁRIO, Marcela Inafuku. A judicialização na expansão das vagas em creches: o diálogo entre poder judiciário e poder executivo. 2017 Dissertação. [Formação de Gestores 
Educacionais] Universidade Cidade de São Paulo, São Paulo, 2017.

ROSEMBERG, Fúlvia. O movimento de mulheres e a abertura política no Brasil: o caso da creche. Cadernos de Pesquisa. São Paulo, v. 51, p.73-79, nov. 1984.Disponível em: http:// publicacoes.fcc.org.br/ojs/index.php/cp/article/view/1462/1457 Acesso em: 10 jan. 2020.

SANTO ANDRÉ. [Prefeitura Municipal de Santo André/Secretaria de Inclusão e Assistência Social. Secretaria de Orçamento e Planejamento Participativo. Departamento de Indicadores Sociais e Econômicos]. Panorama da Pobreza em Santo André. Disponível em: http://www. santoandre.sp.gov.br/pesquisa/ebooks/370221.PDF. Acesso em: 28 nov. 2020

SANTOS, Marinella Burgos Pimentel dos. Análise dos efeitos da judicialização da política pública de educação infantil: o caso de Santo André (SP). Dissertação de mestrado em Gestão e Políticas, Escola de Administração de Empresas de São Paulo, Fundação Getúlio Vargas, São Paulo, 2014.

\section{SILVA, M.P. Defensoria Pública na Judicialização da Educação Infantil no Município} de São Paulo: efeitos institucionais e sobre as políticas públicas. Dissertação [Mestrado em Políticas Públicas] Universidade Federal do ABC, Santo André, 2018.

TAPOROSKY, Barbara Cristina Hanauer; SILVEIRA, Adriana Dragone. A judicialização das Políticas Públicas e o Direito a Educação Infantil. Revista EccoS. São Paulo, $\mathrm{n}^{\circ}$ 48, jan/mar, 2019. Disponível em: https://periodicos.uninove.br/index. php?journal $=$ eccos \&page $=$ article $\&$ op $=$ view $\&$ path $\% 5 \mathrm{~B} \% 5 \mathrm{D}=8118 \&$ path $\% 5 \mathrm{~B} \% 5 \mathrm{D}=6616$ Acesso em: 10 jan. 2020.

XIMENES, Salomão Barros; OLIVEIRA, Vanessa Elias de; SILVA, Mariana Pereira da. Judicialização da educação infantil: efeitos da interação entre o Sistema de Justiça e a Administração Pública. Rev. Bras. Ciênc. Polít., Brasília, n. 29, p. 155-188, Ago. 2019 . Disponível em: http://www.scielo.br/pdf/rbcpol/n29/2178-4884-rbcpol-29-155.pdf Acesso em: 15 jan. 2020.

Data de Submissão:01/02/2020

Data de Aceite:03/04/2020 